\title{
WISDOM LESSONS BASED ON THE “CYTOKINE-STORM” METAPHOR
}

\begin{abstract}
The basic process of COVID-19, and especially the kernel of its deadly impact: the cytokine storm, is discussed. Destructive positive feedback is started by messenger cells that become and act blindly for their impact. They become "de-cognitive" and "de-communicative". Such process of deterioration of messengers is a relevant metaphor to understand and approach some relevant aspects of wisdom in social systems, in economic systems, in political systems...
\end{abstract}

Keywords: Canon, cytokine-storm, de-cognition, de-communication, expert, metaphor, postmodernism, Protagoras, wisdom.

Introduction

Wisdom is a very complex phenomenon, which includes a lot of different aspects. We have learned that Covid-19 and especially the "cytokine storm", which is responsible for the high percentage of deaths as a consequence of the COVID-19-infection, can contribute a lot to the better understanding of some vital aspects of wisdom. The cytokine-storm metaphor and the application of this metaphor are very useful in the present-day social, cultural, climate, political and other crises and disasters.

In the studies of and approaches to wisdom, not much attention is paid to the aspects of decognition and de-communication. Still, the basic plot of the so well-known Greek classical tragedies as well as of the so popular operas is related to phenomena of de-communication as well as de-cognition. What we mean is that the main heroes of the plots are victims of cognitive and communicative blinding: misunderstandings, wrong interpretation of signals, symbols, etc. what leads to the fall, the destruction of the hero...

One can argue that an important aspect of wisdom is to detect, to avoid, to deter, to correct processes which generate cognitive and communicative inactivation. These processes can be started, generated, strengthened, guided by selfdeception but also in a lot of cases purposely started by individual or group dyssocials, hypocrites, perverts-narcissists.

To stop to be open to signals from others, friends as well as enemies, from the environments, as well as to stop to inform, to send signals to others, friends as well as enemies, the environments, is to start de-communication. To stop to ponder, to interpret, to look at the consequences and causes, to stop to look at how to react, to ameliorate, to stop or change destruction etc., is to start de-cognition.

For wisdom, it is crucial to pay attention to such processes of de-communication and de-cognition. At least these processes of de-communication and de-cognition may not be manipulated 
by others in function of abusing individuals, groups, populations, to control and to bring them into submission. Temporarily self-de-communication and self-de-cognition by an individual or group, in view of elaborating growth, realizing one's own views, targets, ideals can be useful and interesting. This, however, has to be selective, temporary closing in oneself or the own group for better blossoming, or at least to have the chance to open a budding talent... Such decommunication and de-cognition require a high level of wisdom to avoid blindness and implosion or explosion of oneself or the own group. This requires a very sophisticated strategy of combined communication and de-communication and cognition and de-cognition.

In the present development concerning the climate crises and challenges, the racial discrimination challenges and the challenges concerning military conflicts, as well as the economic and social challenges of more and more poverty with a small group of the super-rich, we see that decognition and de-communication are strategically used for blinding the general public as well as their leaders, for avoiding to introduce real solutions to problems, which are only becoming larger and larger, more and more insolvable. The cytokine-storm metaphor illustrates these processes of de-communication and de-cognition, their dangers, their irreversible destructions and impact. However, they too illustrate that there are ways to stop the de-cognition and de-communication and how there are ways to start to reverse these processes and how to make stronger and better the cognition and communication processes... towards more wisdom and therefore, survival with well-being and well-being with survival.
The "Cytokine Storm" and

"Cytokine Storm" Metaphor

The body's immune system responds to viruses and bacteria in the first place. In some people, a very reactive immune system can lead to a massive inflammatory storm: a cytokine storm. Such a storm can overwhelm the lungs and other organs. In those cases, it is not an aged or weakened immune system that is the problem - it is one that works too well. The positive feedback loop of cytokine creation turns here into a "cytokine storm", a situation in which excessive cytokine production causes an immune response that can damage organs, especially the lungs and kidneys, and even lead to death (Osterholm, 2005; Poltorak, 2020; Tisoncik, 2020; Alison, 2020).

To coordinate their attack on infection, the cells involved in the body's immune response need to communicate with each other. They do this by releasing a set of proteins that serve as chemical messengers. These proteins, called cytokines, tell immune cells what to do and also tell the body to produce more of them to help deliver a knockout blow to the infection.

Cytokines are an integral part of the body's immune response, but they are also involved in producing many of the familiar, and less welcoming symptoms of infection. Should we blame the cytokines for triggering fever, inflammation, runny nose and aches often associated with by example a case of the flu? While these side-effects can be unpleasant, an effective multipronged attack depends on the organizing power of cytokines.

However, cytokine production can grow out of control. Immune cells release cytokines that tell the body to produce more immune cells, and 
in turn, these new cells release even more proinflammatory cytokines, a subset of cytokines, known as chemokines. These are critical in the recruitment of cells to sites of inflammation and help to fight pathogens - but this process can have an overall detrimental effect. The positive feedback loop of cytokine creation can lead to the above mentioned "cytokine storm".

In the case of cytokine storms, these cytokine cells start to behave autonomously, in positive feedback. They are no longer taking into account the real need in the localization. The "observation", "description", "interpretation" tasks: a kind of cognitive activity of the messenger cell, as well as communicative activity (the transmission of the actual situational needs), are becoming void. This means that the cytokine cells are becoming "de-cognitive" and "de-communicative", that is, blind messengers, which keep on triggering. The inertia is taking over the cognitive and communicative tasks. These are put in a kind of sleep mode and taken over by autonomous continuous preexistent action. Therefore the necessary change in action is stopped. That leads to killing the organism if the inertia: the decommunication and de-cognition is not stopped in time and reactivated to trigger the necessary changed actions.

We see these processes of de-communication and de-cognition of the messengers not only in the immunological system of the body. We see these also in social systems, in economic systems, in political systems and in climate management systems. It is very crucial to recognize these "cytokine storms", and to be able to reverse the de-communication and de-cognition developments of messengers: experts in the social, cultural, economic, cultural, religious and climate environment.

Cytokine storms get much attention because they are so dramatic. Their potential to do serious harm is genuinely real, especially in a population with robust immunity. While cytokine storms can result from several different types of infections and autoimmune conditions, research indicates they often result from exposure to certain strains of influenza. Scientists now believe that cytokine storms caused many of the deaths associated with the "Spanish Flu" pandemic of 19181920 and the more recent outbreaks of bird flu, flu, COVID-19...

In other illnesses, we see the same dangerous developments. Take, for instance, Ulcerative colitis and the Crohn's disease. The "cytokine storm" phenomenon can be found here too. As an efficient solution to stop the "storm": the positive feedback, one applies here, in mild or in severe cases, with success: Interleukine-6. We can see that, in worse cases of COVID-19, one has also used with success this Interleukine-6. The phenomenon of the "cytokine storm" is also known under the label "Kawasaki disease" when it is present in babies or young children. The same has to be said on croup in children, asthma exacerbations, rheumatoid arthritis and for some conditions that cause brain swelling. Here Dexamethasone, a steroid-based medication has long been used in the treatment of these "storms" with success. Part of the way how it works is by suppressing the immune system. What we do know about patients that suffer the worst complications of COVID-19, such as breathing difficulties, is that their own immune system overresponds to the virus, so as well as attacking infected cells it also attacks healthy cells such as those found in the lungs. Dexamethasone helps prevent this over-reaction so that the immune system targets only infected cells. Studies show that the drug reduced the number of deaths in coronavirus patients requiring a ventilator by 
one-third, and for those requiring oxygen, the number of deaths was reduced by one-fifth (Khan, 2020).

On the level of society: cultural, political, economic, climate management one sees analogical processes. In all these domains too, one finds analogous to cytokines and chemokines: "messengers, scouts, spies, experts...". These too, execute processes of observation, interpretation, generalization, warning, search for support, feedback, optimization, etc. ... Moreover, like in the immunological systems we have here also the danger of "cytokine storm" that is the generation of positive feedbacks which endanger, destruct healthy subsystems and systems which are intended to be defended. All this based on intervention by messengers, experts, scouts leading to de-cognition and de-communication activities between the messengers, experts, scouts, and between these messengers and the global command and control systems.

One of the most dangerous aspects here is that once the de-cognition and de-communication of and between the messengers, experts starts, the dangerous unlimited positive feedback can easily start.

\section{Cytokine-Storms are Grounded on Processes of De-Cognition and De-Communication}

The positive feedback started by the selfdestructive "cytokine-storms" is grounded in the dysfunction of the "messengers", the experts who fire action, not taking into account the relevant change in the environment. This is critical in all types of processes and environments, be it immunological, social, economic, ecological, climate processes, etc. ... In fact we can say that always there is a grave danger that the messen- gers, the experts, the scouts are weakening, even losing their cognitive and communicative activity and efficiency. This is a great problem and danger of messengers, experts, and even actors in general. Messengers, experts, actors have a certain set of implicit or explicit cognitive and communicative tasks which they are expected to execute.

We know that the environment can implicitly or explicitly stimulate or weaken the execution of some cognitive and communicative tasks expected from actors, or charged to some actors...

In the case the environment weakens implicitly or explicitly the readiness to execute specific cognitive or/and communicative tasks, we see processes of "de-cognition" and "de-communication" of the actors involved.

Be aware that in each society, some processes: rituals can activate the processes of "de-cognition" and "de-communication" of actors. This is an essential social strategy, to generate "harmony" in society, by stimulating the cognitive and communicative potentials of some actors, and deactivating the cognitive and communicative potentials of other actors by introducing rituals for empowering some individuals, and by disempowering others... These processes of de-cognition and de-communication can become very dangerous, under some circumstances indeed if they lead to one or another type of positive feedback.

What type of de-cognition and de-communication, we can detect with the messengers, experts and actors? We can easily introduce three basic types of de-cognition and de-communication. Let us start with de-cognition.

Concerning cognition, we have to take into account that there exists several types of intelligence: rational, emotional, caring intelligence, etc. Some authors differentiate about 15 types of 
intelligence (Vandamme, Rousseaux, \& Wang, 2013). One way of de-cognition concerns the narrowing of the types of intelligence that are active in use. The second type of de-cognition happens when a particular type of intelligence is used; some other types of intelligence or subsystems are being inactivated. Take, for instance, rational intelligence. One can differentiate several sub-processes as observation, interpretation of the observations, the prediction of expected consequences, the generation of possible actions, the evaluation of the adequacy of the possible actions, the correct activation and execution of actions etc. Some of these sub-processes can be eliminated, simplified, made inactive. These are all part of the second type of de-cognition. The third type of de-cognition concerns the generation of internal brain opiates (which also can deactivate cognition and communication skills). Such production can be stimulated by external social media, etc (Austin, 2001, pp. 216-223).

Analogous remarks can be made on the deactivation of communicative skills. We can differentiate a lot of different forms of communication (verbal, non-verbal, several languages, etc.). For each specific type, one can differentiate between one way, two ways or multiple ways of communication. Finally, one has also to take into account the internal or external brain opiates and their effect on the deactivation of the several communication variants. The "social media", games, Netflix's, etc. stimulate the production of endogenous opioids by brain itself. These endogenous opioids have a great impact among others on breathing, fear, pain and suffering, mood, novelty, motoric autism and motivational drive, conditional responses and muscle tone and moreover on de-cognition and de-communication. This de-cognition and decommunication stimulate the successes of an individual as well as group hypocrites: dyssocials or perverted narcissists.

The Struggle for Wisdom from the Perspective of the "CYTOKINE-STORM" METAPHOR or How to Detect and Reverse the De-Cognition and the De-Communication Processes in Education, in Social Media, in Cultural Developments, in Climate, Economic, Technical and Political Challenges and Creativity, in Learning and Using Critical Thinking...

\section{Cytokine Political Storms}

On the level of society concerning political, democratic organizations, we regularly see "cytokine storms". "Cytokine storms" we have here when the immune system 'messengers': we call them here 'political cytokines', get into positive feedback and start to destruct healthy and vital own subsystems of society, organizations... and finally, destruct sometimes even the whole system. With the cytokines we mean on the level of the political, juridical society, the "messengers, spies, scouts, experts" working for the repressive systems: the military, police, secret police, the judiciary etc.

Experts, in general, are influencers who are able to control, activate and deactivate decision-makers. These experts are very dependent on their general as well as on their situational, local and global knowledge. The more urgent and vital the decisions to advice or/and to make, the stronger the tendency to start decognition ("de-cognition", in other words, blindly carrying out an action, without thinking about the consequences of its actions, in the specific environment) and de-communication. The stronger the de-cognition and decommunication, the more danger to start and 
to continue positive feedback (Vandamme, Wang, Albiñana, \& Kaczmarsky, 2014; Vandamme \& Cotton, 2013; Rousseaux, Wang, Kaczmarski, \& Vandamme, 2017).

\section{Social, Cultural and Religious Cytokine Storms}

On the level of society, social, cultural, religious, etc. organizations, we see a lot of "cytokine storms". "Cytokine storms" we have here when the immune system 'messengers': social, cultural or religious cytokines, we mean: "the social, cultural or religious spies, scouts, experts, public leaders, etc. use their influence on control systems, to start and continue positive feedback which ends up in starting to destruct healthy and vital own subsystems of society,... There are a lot of such cultural "cytokine storms" in history. Think of the 16th-century iconoclastic fury, religious wars, racist movements, killings and destructions..., nearly everywhere in the world throughout history (Vandamme \& Kaczmarsky, 2012; Vandamme, 1972; Wang et al., 2009; Wang, Balder, \& Vandamme, 2019; Rousseaux, Wang, \& Vandamme, 2012).

\section{Economic Cytokine Storms}

On the level of economic "cytokine storms", we refer to 'messengers' that we call economic Cytokines. These inform and influence as observers, scouts, experts (economists, economic journalists...) the public and responsible economic decision-makers to lead and to intervene in the economic developments, the infrastructures, the social, cultural, political and the repressive and juridical environment, in favour of realization of the economic targets, values, etc. Here too the dangers exist that the messengers: the economic cytokines work too well and start in positive feedback to destruct healthy and vital economic subsystems and infrastructures..., because of the responses to economic dangers and expected or started disasters, but misguided by the de-cognition and de-communication (Houston, McCune, \& Osbourne, 2011; Kaczmarsky, Albiñana, Vandamme, \& Wang, 2012; Vandamme, 2013).

\section{Climate Cytokine Storms}

On the level of climate "cytokine storm", we refer to 'messengers' we call climate cytokines, when individuals who, as climate observers, scouts, experts (weatherman, weatherwoman...) inform the public and responsible organizations and more importantly influence political, economic, repressive and juridical decisionmakers to intervene and protect the people, the infrastructures etc. Here too the dangers of the cytokines exist the climate experts, messengers who work too well and who start positive feedback which destruct healthy and vital subsystems and infrastructures... and finally, the whole climate system, in view of responding to climate dangers and expected or started climate disasters? All this based on a process of de-cognition and de-communication, started by one or another process that has not been detected and corrected in time!

\section{The Struggle for Wisdom as a Rediscovery or Recreation by Post-Modernism of Protagoras' Strict-Nominalism as Well as Taoism or Gnosticism}

Post-modernism accentuates the creation by language, by words, of realities which are changing our world, our beliefs over the world and in this world. It creates implicit and explicit ideals, which promises happy futures (Vandamme, 2006)... However, the first and second World 
Wars proved that these language creations, ideals, these promises, can end up in the destruction of the ideals, of innocent environments, of humans as well as non-humans. This belief in the power of words: "nomen", but also the awareness of weakness and danger of words is also the underlying common kernel of the Protagorean perspective: sometimes called strict-nominalism, as well as Gnosticism (the Mesopotamian as well as the early Christian Gnosticism), or the Taoist view on the power and challenge of words and language. In this perspective, one can argue that the so popular post-world war relativism on art and philosophy including the existentialist relativism and epistemological viewpoint on language and the power of words, is in fact a rediscovery or perhaps even a recreation of age-old Protagorean, gnostic as well as Taoist viewpoint and challenges. In this perspective, in view of stimulating wisdom, we can formulate some principles, paradigms which can help to found, to stimulate and support the utterly vital antidote against the de-cognition and de-communication processes.

We can mention here the following principles, paradigms (Vandamme et al, to be published 2020):

1. minimalize oppressive "harmony",

2. stimulate the parallel use of multiple forms of intelligence,

3. stimulate the conscious construction and deconstruction of knowledge, being aware of the relativity of the results. Be prepared to stop the use of specific constructions given the effect and impact however attractive and even holy they may have been considered. Each construction is only fruitful and relevant at a particular time in a particular environment. If the environment changes so can also the relevance disappear and even be transformed from a blessing into a pest...

4. Be aware that destructivity is a possible criterium for negative wisdom or pseudo-wisdom. It is true, destruction can be a precondition for new growth, but it can as well be a warning for "negative wisdom". In view of constructive harmony against oppressive harmony, the degree and quality of the destruction is at least "a danger" to be considered carefully and to be questioned. World history illustrates this. Think among others about the Roman conquests. The colonial expansions and conquests are other impressive examples. Above all, we have to think about the XX and XXI century "wild growth and proliferation" of scientific development and technical conquest of the environment, the climate and their unwise impacts (Vandamme, 2013; Vandamme, 2019).

\section{Identity Creation as a Challenge of}

Wisdom in Managing Cognition, De-Cognition,

Communication and De-Communication

Countries, cultures like to strengthen the unity of their people, inhabitants. In history, again and again one is trying to create this unity, by elaborating and describing the history, the achievements, the successes... of the country, the culture in order at the same time to build and create an ideal identity of the inhabitants... In this perspective, one sees the development sometimes even of a "canon" on the history and reality of the country. Such canon is then used as the basis of the school education curriculum as well as of the curriculum for the integration of immigrants (Reynebeau, 2020).

Several challenges one meets when one tries to elaborate such canon concerning the nati- 
onal, cultural, economic, political, etc. history and reality in view of the creation and of strengthening the national identity. A "canon" targets a description and overview of the main parts and achievements of a country or culture.

So, it is very attractive to elaborate for one's country the efforts and successes in history and at present with even a perspective of a bright future of the own developments, expansion, growth, enlargements of progress, in cultural, political, scientific, technological, economic, agricultural etc. domains. For sure one has to take into account that progress, expansion, growth, also produce risks of failures and unpleasant side-effects. Moreover, it generates not only risks but sometimes real disasters.

Another challenge in generating such canons, is that events, results which were seen in, e.g. the $13^{\text {th }}$ century or $18^{\text {th }}$ century as very positive, something then to be very proud of, can be in the present day, say the $21^{\text {st }}$ century, something to be ashamed of...

So when elaborating a canon on the history of one's country, to strengthen the common ideal identity of the own inhabitants: school children, immigrants, in order to stimulate their pride to take part and to contribute to the development of the people, the country, it is a big challenge what to choose and to integrate in the canon. It will be very attractive but probably unwise to select only these parts of the history which are easily integrated in a heroic, beautiful positive picture, based on and targeting an uncritical and narrowminded interpretation and view on history to create a de-cognitive and de-communicative audience: children, immigrants.

To illustrate the point and challenge, let us refer to some actual developments in the world concerning racism, colonialism, religious intolerance, genocide, etc. In the $20^{\text {th }}$ century, in most
Western European countries, one was very proud of the colonial expansion of their countries: Great Britain, France, Germany, the Netherlands, Belgium, the USA... One was proud of the prosperity which was created, the power, etc.... However this expansion, progress, growth, enlargement generated also some unpleasant consequences, dangers, intolerance, which generated a lot of cruelty, genocides, destruction: cultural, biological, environmental, etc. How to cover that in a canon, which is not targeting blinding the audience, through careful and intensive decognition and de-communication strategies?

The challenge of wisdom is the elaboration of a "historical-cultural canon" of a country, not through a one-sided description of the history, the present and the future targets, with attention only for the positive presentation of the own history. It is necessary at the same time to elaborate on the dangers of the expansion, the growth, the achievements as well the possible as the real failures. This in order to stimulate the critical cognition and communication on the achievements in view of recognizing the necessity to try always for better... Recognizing the failures which have been made. How these failures may be met today and in the future? More important even, how to avoid the same mistakes, failures. How to learn from them... How it could have been in another way, perhaps with better or even worse results, etc.?

Thus, a canon is not and may not be a glorified overview and presentation of a country and its history but rather an overview of the challenges of a country, in the past, the present and the future, not only with its successes, failures, strengths and weaknesses but also with the promises that it will wisely tackle those challenges.

In such a canon, from a wisdom point of 
view, one is integrating and taking into account the dangers of de-cognition and de-communication, and stimulating rather the cognitive and communicative processes. Therefore such canon targets to:

1. describe and list the positive results and attempts: take them into account, pay attention to, and discuss them,

2. elaborate the dangers of the expansion, growth, progress. Dimensions to take into account can be genocide (e.g. Matins of Bruges at the Battle of the Golden Spurs in 1302, an example of a real or mythical small-scale genocide of people speaking a different language), exploitation, slavery, destruction and mutilation of the environment, cultures, populations...(Cf. colonization...)

3. weigh up the promises as well as the dangers of scientific and technological development: impact on the environment, health, climate; impact on the food chains and food quality; impact on dangerous and polluting packaging (plastics), use of dangerous additives, excessive intake of sugars, fat, hydrated fats, etc.

\section{Conclusion}

Sometimes new dramatic events like COVID-19 and cytokine-storms bring into the fore phenomena, features that are perhaps already implicitly present in our general knowledge, theoretical and practical know-how but that are needed to be brought explicitly in our theories and know-how. Nowadays, concerning wisdom, one can propose on the base of COVID-19 as well as the cytokine-storm - responsible for a dramatic impact worldwide and a high mortality rate, to make explicit the underly- ing mechanism of "de-cognition" and "de-communication" present in the immune system and to make it explicit as a metaphor-based on this, in epistemology, in knowledge acquisition as well as in knowledge systems and artificial intelligence. Above all, there are interesting parameters for understanding, elaborating and searching for wisdom.

\section{REFERENCES}

Alison, G. (2020). Cytokine Storm. New Scientist. Retrieved July 27, 2020 from: https://www.newscientist.com/term/cyt okine-storm/.

Austin, J. H. (2001). Zen and the Brain. Cambridge: The MIT Press.

Houston, M., McCune, V. \& Osbourne, M. (2011). Flexible Learning and Its Contribution to Widening Participation: A Synthesis of Research. York: Higher Education Academy.

Kaczmarsky, P., Albiñana, D., Vandamme, F., \& Wang, L. (2012). Educative Framework for Higher Computer Education. Scientia Paedagogica Experimentalis, XLIX(1-2), 83-114.

Khan, A. (2020). Doctor's Note: Can dexamethasone treat COVID-19? Al Jazeera, 20 June 2020. Retrieved July 27, 2020 from: https://www.aljazeera.com/indepth/features/doctor-note-dexamethasone-treat-covid-19-200515154943918.html.

Osterholm, M. (2005). Preparing for the Next Pandemic. The New England Journal of Medicine, 352(18), 1839-1842. doi: 10.1056/NEJMp058068.

Papacharissi, Z. (2009). The Virtual Geographies of Social Networks: A Comparative 
Analysis of Facebook, Linked in and a Small World. New Media Society, 11, 199-207.

Poltorak, A. (2020). Blocking a Cytokine Storm is Vital for Treating COVID-19. Retrieved July 27, 2020 from: https://www.weforum.org/.

Reynebeau, M. (2020). De identiteit is net zo vloeibaar als de geschiedenis. De standaard, 24 June. Retrieved July 27, 2020 from: https://www.standaard.be/cnt/dmf20200623 04999394.

Rousseaux, M., Wang, L., \& Vandamme F. (2012). CUPIE-do, an Approach to Learning Fatigue in a Holistic Perspective. Scientia Paedagogica Experimentalis, XLIX(1-2), 21-40.

Rousseaux, M., Wang, L., Kaczmarski, P. \& Vandamme, F. (2017). Het leeractieteam CUPIEDO. Leermoeheid in een holistisch perspectief. Gent: Communicatie \& Cognitie.

Tisoncik, J. R. (2020). Into the Eye of the Cytokine Storm. NCBI. Retrieved June 26, 2020 from: https://www.ncbi.nlm.nih.gov/.

Vandamme, F. (1972). Simulation of Natural Language. The Hague: Mouton.

Vandamme, F. (2006) Protagoras, Stromingen in de Wijsbegeerte. Gent: Communication $\&$ Cognition.

Vandamme, F. et al. (to be published 2020). The Post-Genetic Cultural Man. Gent: Communication \& Cognition.
Vandamme, F. J. (2013). Het Ware Verhaal van Hiram. Phoenix collectie. Gent: Communicatie \& Cognitie.

Vandamme, F. J. (2019). De uitdagingen van het recht. De Witte Lotus collectie. Gent: Communicatie \& Cognitie.

Vandamme, F., \& Cotton, A.-M. (2013). Marc Spoelders: Homo Pedagogicus; a Contributor to education for wisdom and harmony. Scientia Paedagogica Experimentalis, $L(1-2), 25-53$.

Vandamme, F., \& Kaczmarsky, P. (2012). Thesauri and Education Use and Exploitation through Individualisation in a Harmony Perspective. Scientia Paedagogica Experimentalis, XLIX(1-2), 4162.

Vandamme, F., Rousseaux, M., \& Wang, L. (2013). Learning in a Holistic Perspective: the CUPIE-do Frame. Communication \& Cognition, 46(1-4), 23-37.

Vandamme, F., Wang, L., Albiñana, D., \& Kaczmarsky, P. (2014). Social Media and Education. Dangers and Promises: A Call for Cooperation. Communication \& Cognition, 47(1-4), 49-116.

Wang, L. et al. (2009). Confucius sleutel naar de toekomst? Gent: Communication \& Cognition.

Wang, L., Balder, M., \& Vandamme, F. (2019). Harmony, Conflict, versus Communication, Cognition, Decommunication and Decognition. Communication \& Cognition, 52(3-4), 115-160. 